\title{
Functional capacity before and after cardioversion of atrial fibrillation: a controlled study
}

\author{
A T Marcel Gosselink, Harry J G M Crijns, Maarten P Van Den Berg, \\ Stan A J Van Den Broek, Hans Hillege, Martin L J Landsman, Kong I Lie
}

\begin{abstract}
Objective-To evaluate the effect of cardioversion on peak oxygen consumption (peak $\mathrm{Vo}_{2}$ ) in patients with long-standing atrial fibrillation, to assess the importance of underlying heart disease with respect to the response to exercise, and to relate functional capacity to long-term arrhythmia outcome.
\end{abstract}

Design-Prospective controlled clinical trial.

Setting-Tertiary referral centre.

Patients- 63 consecutive patients with chronic atrial fibrillation accepted for treatment with electrical cardioversion. Before cardioversion all patients were treated with digoxin, verapamil, or a combination of both to attain a resting heart rate $\leqslant 100$ beats per minute.

Interventions-Electrical cardioversion.

Main outcome measures-Peak $\mathrm{Vo}_{2}$ measured before and 1 month after electrical cardioversion to compare patients who were in sinus rhythm and those in atrial fibrillation at these times. Maintenance of sinus rhythm for a mean follow up of 19 (7) months.

Results-Mean (1SD) peak $\mathrm{Vo}_{2}$ in patients in sinus rhythm after 1 month $(n=37)$ increased from $21 \cdot 4(5 \cdot 8)$ to $23 \cdot 7$ (6.4) $\mathrm{ml} / \mathrm{min} / \mathrm{kg} \quad(+11 \%, \quad P<0.05)$, whereas in patients with a recurrence of atrial fibrillation 1 month after cardioversion $(n=26)$ peak $\mathrm{Vo}_{2}$ was unchanged. In patients who were in sinus rhythm both those with and without underlying heart disease improved, and improvement was not related to functional capacity or left ventricular function before cardioversion. Baseline peak $\mathrm{Vo}_{2}$ was not a predictive factor for longterm arrhythmia outcome.

Conclusion-Restoration of sinus rhythm improved peak $\mathrm{Vo}_{2}$ in patients with atrial fibrillation, irrespective of the presence of underlying heart disease. Peak $\mathrm{Vo}_{2}$ was not a predictive factor for long-term arrhythmia outcome after cardioversion of atrial fibrillation. These findings suggest that cardioversion is the best method of improving functional capacity in patients with atrial fibrillation, whether or not they have underlying heart disease and whatever their functional state.

(Br Heart f 1994;72:161-166)
In atrial fibrillation, loss of atrial contraction and an excessive response of heart rate to exercise may be detrimental to cardiac output because they impair ventricular diastolic filling. ${ }^{1-4}$ As a consequence, functional capacity in patients with atrial fibrillation may be reduced. ${ }^{5}$ Though cardioversion of atrial fibrillation is often performed its effect on functional status has not been extensively studied. Measurement of peak oxygen consumption (peak $\mathrm{VO}_{2}$ ) by gas exchange analysis is an accurate and objective non-invasive method of determining functional capacity. ${ }^{6-10}$ So far, there have been only three small studies of the effect of cardioversion on peak $\mathrm{VO}_{2}$ in atrial fibrillation. ${ }^{11-13}$

The aim of the present prospective study was to analyse the effect of cardioversion on peak $\mathrm{VO}_{2}$ a month after cardioversion in a large cohort of patients with long-standing, chronic atrial fibrillation; patients who had a relapse of atrial fibrillation served as a control group. We also studied the importance of underlying heart disease with respect to functional capacity in atrial fibrillation and assessed the predictive value of functional capacity for long arrhythmia outcome by measuring baseline peak $\mathrm{Vo}_{2}$.

\section{Patients and methods}

PATIENTS

All consecutive patients with chronic atrial fibrillation selected between June 1989 and February 1992 to undergo electrical cardioversion were eligible for the study. Exclusion criteria were (a) paroxysmal atrial fibrillation; $(b)$ myocardial infarction within the past 6 months; (c) thyroid dysfunction; $(d)$ use of $\beta$ adrenergic blocking agents; and $(e)$ angina, chronic obstructive pulmonary disease, claudication, or any other abnormality intefering with the performance of a treadmill exercise test. The study was approved by the Institutional Review Board and informed consent for participation in the study was obtained from all patients.

\section{STUDY DESIGN}

Patients underwent exercise testing a day before and 4 weeks after cardioversion. In all patients anticoagulant therapy was started to maintain prothrombin time within a target range of $1.5-2.0 \times$ control at least 4 weeks before cardioversion. Atrioventricular nodal blocking drugs (digitalis, verapamil, or both) were titrated to attain a resting heart rate
Accepted for publication 13 December 1993 
$\leqslant 100$ beats per minute at least 2 months before cardioversion. Twenty patients were taking antiarrhythmic drugs (VaughanWilliams class I, 15 patients; class III, 5 patients). Drug treatment was unchanged throughout the study. Before cardioversion a standard cross sectional echocardiogram was performed in all patients to assess left atrial size and left ventricular function as measured by left ventricular fractional shortening. Cardioversion was carried out according to a previously described protocol. ${ }^{14}$ Patients visited the outpatient department 1,3 , and 6 months after cardioversion and every 6 months thereafter. At each visit a 12 lead electrocardiogram and 24 hour Holter monitoring (Marquette Laser Holter System, Milwaukee, Wisconsin, USA) were performed to determine the rhythm. Exercise data for patients who were in sinus rhythm 1 month after cardioversion were compared with those of patients who could not be cardioverted or had a relapse of atrial fibrillation 1 month after cardioversion.

\section{EXERCISE TESTING WITH RESPIRATORY GAS ANALYSIS}

Exercise testing with measurement of respiratory gas exchange was performed while patients exercised on a treadmill according to a modified Naughton protocol. ${ }^{15}{ }^{16}$ Oxygen consumption, carbon dioxide production, and respiratory exchange ratios were measured continuously during exercise by an automated system for measuring gas exchange (Sensormedics system 2900, SensorMedics Corp, Anaheim, California, USA). Values were recorded every $20 \mathrm{~s}$ through an on-line

Table 1 Baseline characteristics of the 63 study patients

\begin{tabular}{|c|c|}
\hline Variable & Value \\
\hline $\begin{array}{l}\text { Age }(y)(\text { mean }(1 \mathrm{SD})) \\
\operatorname{Men}(\mathrm{n}(\%))\end{array}$ & $\begin{array}{l}57(13) \\
44(70)\end{array}$ \\
\hline \multicolumn{2}{|l|}{ Underlying heart disease $(n(\%))^{*}$ : } \\
\hline Ischaemic heart disease & $14(22)$ \\
\hline Rheumatic valve disease & $3(5)$ \\
\hline Mitral valve disease & $15(24)$ \\
\hline Aortic valve disease & $6(10)$ \\
\hline Systemic hypertension & $7(11)$ \\
\hline Congenital heart disease & $5(8)$ \\
\hline Chronic pericardial disease & $1(2)$ \\
\hline Lone arrhythmia & $22(35)$ \\
\hline \multicolumn{2}{|l|}{ Medication (n(\%)): } \\
\hline Digoxin only & $13(21)$ \\
\hline Verapamil only & $14(22)$ \\
\hline Both digoxin and verapamil & $36(57)$ \\
\hline Antiarrhythmic drugs & $20(32)$ \\
\hline Anticoagulants & $63(100)$ \\
\hline Total arrhythmia duration (median (range)) (mnth) & 35 (1 to 288$)$ \\
\hline NYHA class, I,II,III (n(\%)) & $29(46), 23(36), 11(18)$ \\
\hline \multicolumn{2}{|l|}{ Echocardiographic measurements (mean (1SD)): } \\
\hline Left atrial size, long axis view (mm) & $44(7)$ \\
\hline Left ventricular end diastolic diameter (mm) & $52(7)$ \\
\hline Left ventricular end systolic diameter ( $\mathrm{mm}$ ) & $37(8)$ \\
\hline Left ventricular fractional shortening (\%) & $30(7)$ \\
\hline \multirow{2}{*}{\multicolumn{2}{|c|}{$\begin{array}{l}\text { Exercise testing before cardioversion (mean (1SD)): } \\
\text { Rest }\end{array}$}} \\
\hline Rest & \\
\hline HR (beats per minute) & $93(19)$ \\
\hline $\mathrm{SBP}(\mathrm{mm} \mathrm{Hg})$ & $133(20)$ \\
\hline $\mathrm{DBP}(\mathrm{mm} \mathrm{Hg})$ & $84(10)$ \\
\hline \multicolumn{2}{|l|}{ Maximal exercise (mean (1SD)) } \\
\hline HR (beats per minute) & $174(30)$ \\
\hline $\mathrm{SBP}(\mathrm{mm} \mathrm{Hg})$ & $171(24)$ \\
\hline $\mathrm{DBP}(\mathrm{mm} \mathrm{Hg})$ & $85(12)$ \\
\hline Exercise duration (min) & $19 \cdot 0(4 \cdot 3)$ \\
\hline Peak $\mathrm{VO}_{2}(\mathrm{ml} / \mathrm{min} / \mathrm{kg})$ & $21 \cdot 3(6 \cdot 1)$ \\
\hline$\%$ predicted $\mathrm{Vo}_{2}$ & 77 (19) \\
\hline
\end{tabular}

* More than one per patient; CABG, coronary artery bypass grafting; DBP, diastolic blood pressure; $\mathrm{HR}$, heart rate; NYHA, New York Heart Association; $\mathrm{SBP}$, systolic blood pressure; $\mathrm{VO}_{2}$, consumption. computer assembly (IBM computer systems, IBM Corp, Austin, Texas, USA). Before each exercise test, the flow meter was calibrated with 31 syringe and the gas analysers were calibrated with nitrogen and a standard oxygen/carbon dioxide mixture. Blood pressure was measured with a mercury sphygmomanometer. The electrocardiogram was monitored continuously with a computer-assisted system (Marquette Electronics, Milwaukee, Wisconsin, USA). Twelve lead electrocardiogram recordings were obtained at rest, at the end of each 2 minute stage, and at peak exercise. Before entering the study, patients underwent at least one test to familiarise themselves with this gas exchange analysis. Patients were encouraged to exercise until symptoms forced them to stop. All patients stopped the test because of dyspnoea or fatigue; and in all patients the gas exchange anaerobic threshold (the point at which carbon dioxide production increased disproportionately in relation to oxygen consumption) and a respiratory exchange ratio $>1.0$ were reached. Peak $\mathrm{VO}_{2}$ was defined as oxygen consumption $(\mathrm{ml} / \mathrm{min} / \mathrm{kg})$ at peak exercise calculated as the mean of the values measured during the last minute of exercise. Heart rate during atrial fibrillation was determined by measuring the average heart rate for a $15 \mathrm{~s}$ period. The predicted peak $\mathrm{Vo}_{2}$ was calculated by the following formulas ${ }^{17}{ }^{18}$ :

Men: peak $\mathrm{Vo}_{2}(\mathrm{ml} / \mathrm{min} / \mathrm{kg})=60-($ age $\times 0.55)$

Women: peak $\mathrm{VO}_{2}(\mathrm{ml} / \mathrm{min} / \mathrm{kg})=48-($ age $\times 0.37)$.

Maximal heart rate was compared with the predicted maximal heart rate. ${ }^{19}$

PEAK OXYGEN CONSUMPTION AND LONG-TERM ARRHYTHMIA OUTCOME

To determine the effect of precardioversion functional capacity on long-term maintenance of sinus rhythm we categorised patients in two groups according to the peak $\mathrm{VO}_{2}$ they attained before cardioversion. We used the age and sex predicted peak $\mathrm{VO}_{2}$ of $70 \%$ as the cutoff point. ${ }^{20} \mathrm{We}$ also studied other factors known to influence long-term arrhythmia outcome: arrhythmia duration, ${ }^{21-23}$ left atrial size ${ }^{212324}$ left ventricular function, ${ }^{25}$ presence and type of underlying heart disease, ${ }^{232627}$ and New York Heart Association class. ${ }^{28}$

\section{LONE ATRIAL FIBRILLATION VERSUS}

UNDERLYING HEART DISEASE

To study the influence of underlying heart disease on response to exercise we categorised patients as those with lone atrial fibrillation and those with underlying heart disease. Exercise data before and after cardioversion were compared in both groups.

\section{DEFINITION OF TERMS}

Chronic atrial fibrillation was defined as atrial fibrillation lasting $>6$ months, without intercurrent sinus rhythm. Underlying heart disease was determined from the patient's history and physical examination, as well as from the chest $x$ ray, echocardiography, and coronary angiography when available. Total 
Table 2 Clinical characteristics of patients in sinus rhythm and those in atrial fibrillation 1 month after cardioversion

\begin{tabular}{lcc}
\hline Variable & $\begin{array}{l}\text { Sinus } \\
\text { rhythm } \\
(n=37)\end{array}$ & $\begin{array}{l}\text { Atrial } \\
\text { fibrillation } \\
(n=26)\end{array}$ \\
\hline Age (y) (mean (1SD)) & $56(12)$ & $57(13)$ \\
Men & $25(68)$ & $19(73)$ \\
Underlying heart disease (\%) & $28(76)$ & $13(50)$ \\
Lone arrhythmia (\%) & $9(24)$ & $13(50)$ \\
Medication (\%): & $8(22)$ & $5(19)$ \\
Digoxin only & $8(22)$ & $6(23)$ \\
Verapamil only & $21(56)$ & $15(58)$ \\
Both digoxin/verapamil & $12(32)$ & $8(31)$ \\
Antiarrhythmic drugs & $34(1 \cdot 5-279)$ & $36(1-88)$ \\
Arrhythmia history, total duration (median (range)) (mnth) & & $13(50)$ \\
NYHA class (precardioversion) (\%): & $16(43)$ & $9(35)$ \\
I & $14(38)$ & $4(15)$ \\
II & $7(19)$ & $44(7)$ \\
Echocardiographic measurements (mean (1SD)): & $45(8)$ & $52(6)$ \\
LA, long axis view (mm) & $51(8)$ & $36(7)$ \\
LVEDD (mm) & $36(9)$ & $30(9)$ \\
LVESD (mm) & $31(10)$ & \\
Fractional shortening (\%) & & \\
\hline
\end{tabular}

LA, left atrial size; LVEDD, left ventricular end diastolic diameter; LVESD, left ventricular end systolic diameter; NYHA, New York Heart Association. None of the variables was significantly different.

arrhythmia duration was defined as the duration of the arrhythmia history from the first episode of chronic atrial fibrillation. It was determined by questioning the patient, by examining the patient's medical record, and by reviewing all available previous electrocardiograms.

\section{STASTICAL ANALYSIS}

Data are expressed as mean (1 SD). Median values were used for variables with a nonuniform distribution. To compare the two groups, continuous normally distributed variables were tested by the one way analysis of variance. Variables with an asymmetrical distribution were tested by the Mann-Whitney U-test. Frequencies were compared by the $\chi^{2}$ test for equality of proportions, with Yates's correction for small numbers $(<10)$. Stepwise logistic regression analysis was used to deter-

Table 3 Exercise data and New York Heart Association classification before and 1 month after cardioversion in patients still in sinus rhythm (sinus rhythm maintained) and patients in atrial fibrillation (atrial fibrillation recurred) 1 month after cardioversion (mean (1SD))

\begin{tabular}{|c|c|c|c|}
\hline & $\begin{array}{l}\text { Before } \\
\text { cardioversion }\end{array}$ & 1 month & Pvalue \\
\hline \multicolumn{4}{|c|}{ Sinus rhythm maintained $(n=37)$} \\
\hline HR (beats/min) & $96(21)$ & $75(18)$ & NS \\
\hline $\mathrm{SBP}(\mathrm{mm} \mathrm{Hg})$ & $127(19)$ & $125(21)$ & NS \\
\hline $\mathrm{DBP}(\mathrm{mm} \mathrm{Hg})$ & $82(9)$ & $81(11)$ & NS \\
\hline \multicolumn{4}{|l|}{ Peak exercise: } \\
\hline HR (beats/min) & $175(33)$ & $140(25)$ & $<0.001$ \\
\hline $\mathrm{SBP}(\mathrm{mm} \mathrm{Hg})$ & $164(21)$ & $176(24)$ & $<0.05$ \\
\hline DBP (mm Hg) & $82(13)$ & $82(12)$ & NS \\
\hline Exercise duration (min) & $19 \cdot 3(4 \cdot 9)$ & $23 \cdot 7(6 \cdot 0)$ & $<0.05$ \\
\hline Peak $\mathrm{VO}_{2}(\mathrm{ml} / \mathrm{min} / \mathrm{kg})$ & $21 \cdot 4(5 \cdot 8)$ & $23 \cdot 7(6 \cdot 4)$ & $<0.05$ \\
\hline $\begin{array}{l}\% \text { predicted } \mathrm{Vo}_{2} \\
\mathrm{NYHA} \text { class }\end{array}$ & $77(19)$ & $85(19)$ & $<0.05$ \\
\hline NYHA class & $1.8(0.7)$ & $1.4(0.5)$ & $<0.05$ \\
\hline \multicolumn{4}{|c|}{ Atrial fibrillation recurred $(n=26)$} \\
\hline $\begin{array}{l}\text { Rest: } \\
\text { HR (beats/min) }\end{array}$ & & & \\
\hline HR (beats/min) & $89(15)$ & $88(15)$ & NS \\
\hline SBP (mm Hg) & $125(18)$ & $126(19)$ & NS \\
\hline DBP (mm Hg) & $78(8)$ & $80(9)$ & NS \\
\hline \multicolumn{4}{|l|}{ Peak exercise: } \\
\hline HR (beats/min) & $172(26)$ & $165(27)$ & NS \\
\hline SBP $(\mathrm{mm} \mathrm{Hg})$ & $182(25)$ & $183(29)$ & NS \\
\hline $\mathrm{DBP}(\mathrm{mm} \mathrm{Hg})$ & $89(11)$ & $88(8)$ & NS \\
\hline Exercise duration (min) & $19 \cdot 0(5 \cdot 0)$ & $20 \cdot 3(5 \cdot 2)$ & NS \\
\hline Peak $\mathrm{VO}_{2}(\mathrm{ml} / \mathrm{min} / \mathrm{kg})$ & $21 \cdot 2(5 \cdot 2)$ & $21 \cdot 3(5 \cdot 6)$ & NS \\
\hline$\%$ predicted $\mathrm{VO}_{2}$ & $78(18)$ & $78(18)$ & NS \\
\hline NYHA class & $1 \cdot 7(0 \cdot 7)$ & $1.6(0.7)$ & NS \\
\hline
\end{tabular}

AF, atrial fibrillation; DBP, diastolic blood pressure; HR, heart rate; NYHA, New York Heart Association; SBP, systolic blood pressure; $\mathrm{VO}_{2}$, oxygen consumption; \% predicted $\mathrm{VO}_{2}$, percentage of age and sex predicted peak oxygen consumption. mine predictors of peak $\mathrm{VO}_{2}$ before cardioversion. Life-table analysis was carried out by the Kaplan-Meier method. Survival curves were compared by the log rank test. A $P$ value $<0.05$ was regarded as significant.

\section{Results}

PATIENTS

Sixty three patients were eligible for participation in the study. Table 1 shows their baseline characteristics. Most patients had underlying heart disease. The mean total arrhythmia duration was long.

\section{CARDIOVERSION: IMMEDIATE AND 1 MONTH RESULTS}

Cardioversion was uncomplicated in all patients. Fifty five $(87 \%)$ of 63 patients were successfully cardioverted to sinus rhythm. The clinical characteristics of those patients who could be cardioverted and those who could not were similar. During the first month after cardioversion atrial fibrillation recurred in 18 of those in whom cardioversion had been successful. Thus after a month 37 patients $(59 \%)$ had maintained sinus rhythm and $26(41 \%)$ were in atrial fibrillation. The clinical characteristics of patients in sinus rhythm and those in atrial fibrillation after 1 month were similar (table 2).

\section{EXERCISE DATA BEFORE AND AFTER \\ CARDIOVERSION}

Table 3 shows exercise data before and after cardioversion in patients who were still in sinus rhythm and those who were in atrial fibrillation 1 month after cardioversion. Exercise testing before cardioversion did not show statistically significant differences between both groups. In patients who had maintained sinus rhythm 1 month after cardioversion, mean peak $\mathrm{Vo}_{2}$ increased by $11 \%$, from $21.4(5 \cdot 8)$ to $23.7(6.4) \mathrm{ml} / \mathrm{min} / \mathrm{kg}(P<0.05)$. Figure 1 shows peak $\mathrm{VO}_{2}$ before and after cardioversion in each patient. Improvement of peak $\mathrm{Vo}_{2}$ after cardioversion was not correlated with precardioversion peak $\mathrm{Vo}_{2}$, left ventricular fractional shortening, or changes in (maximal) heart rate after cardioversion. In contrast, peak $\mathrm{Vo}_{2}$ and other exercise variables did not change in patients who were in atrial fibrillation 1 month after cardioversion.

\section{PRECARDIOVERSION PEAK OXYGEN}

CONSUMPTION AND LONG-TERM ARRHYTHMIA OUTCOME

Mean follow up after cardioversion was 19 (7) months. During this follow up atrial fibrillation recurred in $47(75 \%)$ of all patients who underwent cardioversion (including eight patients who could not be cardioverted). Precardioversion peak $\mathrm{Vo}_{2}$ was $\leqslant 70 \%$ of the age and sex predicted value in 28 patients $(44 \%)$, whereas it was $>70 \%$ in the remaining 35 patients. Kaplan-Meier life table analysis showed that there was no significant correlation between functional capacity (that is, age and sex predicted peak $\mathrm{Vo}_{2}>70 \% v \leqslant 70 \%$ ) before cardioversion and long term arrhyth- 


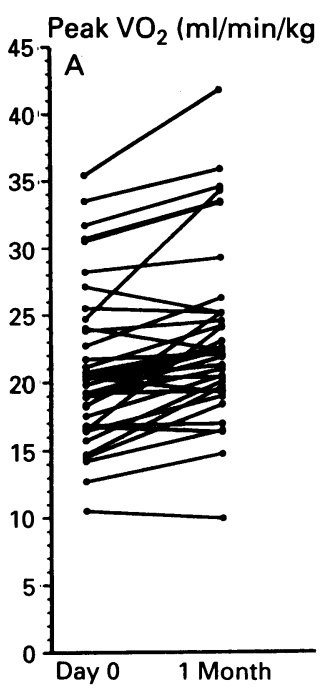

45 Peak $\mathrm{VO}_{2}(\mathrm{ml} / \mathrm{min} / \mathrm{kg}$

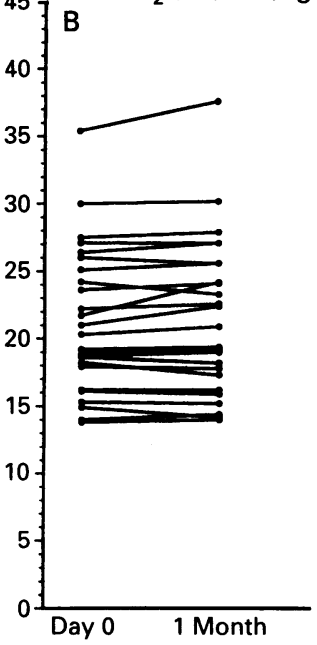

Figure 1 Peak oxygen consumption before and after cardioversion. (A) Patients still in sinus rhythm 1 month after cardioversion. (B) Patients having atrial fibrillation 1 month after cardioversion. Peak $\mathrm{VO}_{2}$, peak oxygen consumption.

Figure 2 Relation between maximal heart rate and peak oxygen consumption during atrial fibrillation. (A) Patients with lone atrial fibrillation. (B) Patients with underlying heart disease. Peak $\mathrm{VO}_{2}$, peak oxygen consumption.
Table 4 Clinical and exercise data (mean (1SD)) of patients with underling heart disease compared with those with lone atrial fibrillation before cardioversion

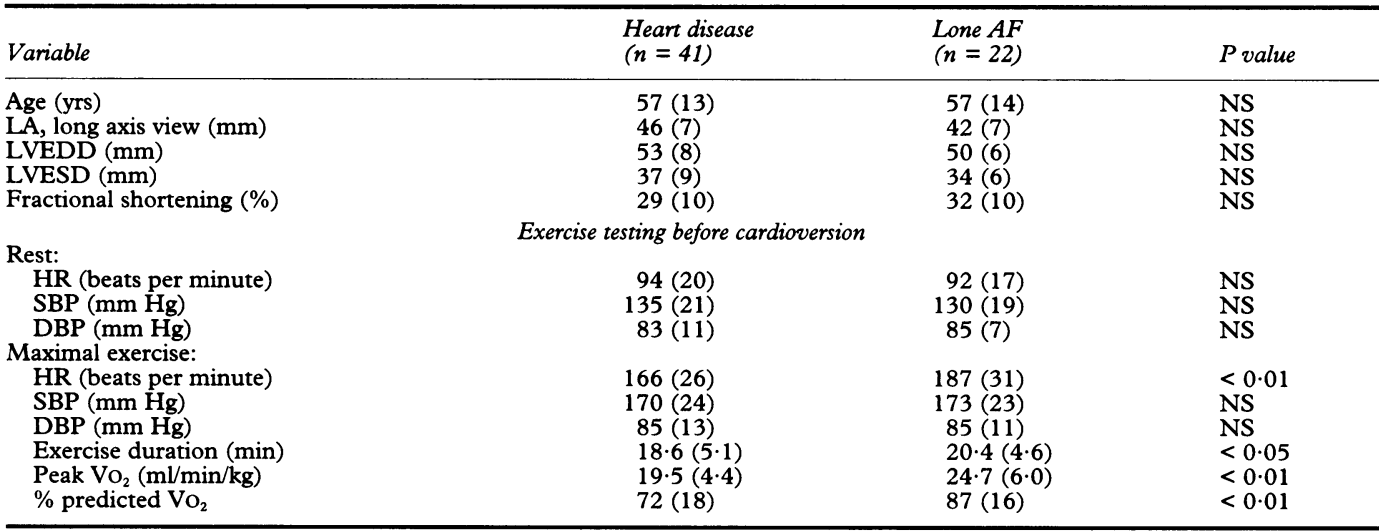

$\mathrm{AF}$, atrial fibrillation; $\mathrm{DBP}$, diastolic blood pressure; $\mathrm{HR}$, heart rate; $\mathrm{LA}$, left atrial size; $\mathrm{LVEDD}$, left ventricular enddiastolic diameter; LVESD, left ventricular endystolic diameter; SBP, systolic blood pressure; $\mathrm{VO}_{2}$ oxygen consumption; $\%$ predicted Vo diameter; LVESD, left ventricular endystolic diameter; SBP, syst
percentage of age and sex predicted peak oxygen consumption.

mia outcome. Thus peak $\mathrm{Vo}_{2}$ was not a predictive factor for the maintenance of sinus rhythm. Also none of the established clinical variables including echocardiographic left atrial size and New York Heart Association class were of predictive value in terms of longterm arrhythmia outcome in the present study.

\section{LONE ATRIAL FIBRILLATION VERSUS \\ UNDERLYING HEART DISEASE \\ Before cardioversion}

Before cardioversion mean peak $\mathrm{Vo}_{2}$ in patients with lone atrial fibrillation was $24 \cdot 7$ $(6 \cdot 0) \mathrm{ml} / \mathrm{min} / \mathrm{kg}$ and $87(16 \%)$ when expressed as a percentage of the age and sex predicted maximum (table 4). Mean peak $\mathrm{Vo}_{2}$ in patients with underlying heart disease was significantly lower than in patients with lone atrial fibrillation: $19.5 \quad(4.4) \quad \mathrm{ml} / \mathrm{min} / \mathrm{kg}$ $(\mathrm{P}<0.01)$ and $72(18 \%)(P<0.01)$ of that predicted. Maximal heart rate was significantly higher in patients with lone atrial fibrillation than in patients with underlying heart disease. In patients with lone atrial fibrillation

there was a significant correlation between maximal heart rate and peak $\mathrm{Vo}_{2}(\mathrm{r}=0.68, \mathrm{P}$ $=0.001$, figure $2 \mathrm{~A})$. There was no correlation in patients with underlying heart disease (figure 2B).

\section{One month after cardioversion}

In patients in sinus rhythm after 1 month, peak $\mathrm{VO}_{2}$ improved both in patients with $(n=28)$ and without $(n=9)$ underlying heart disease, from $19.8(4.8)$ to $22.2(5.2)$ $\mathrm{ml} / \mathrm{min} / \mathrm{kg}(\mathrm{P}<0.05)$ and from $26 \cdot 1(6 \cdot 6)$ to $28.3(7.5) \mathrm{ml} / \mathrm{min} / \mathrm{kg}(\mathrm{P}<0.05)$ respectively (fig 3). The difference in improvement between both groups of patients $(12 \%$ and $8 \%$ respectively) was not statistically significant. In patients without underlying heart disease peak $\mathrm{Vo}_{2}$ after cardioversion was similar to that predicted for controls, whereas in patients with underlying heart disease it was $78 \%$ of that in controls. Resting heart rate and heart rate at peak exercise decreased by $20 \%$ in both groups. Whereas maximal heart rate after cardioversion in patients without underlying heart disease was similar to

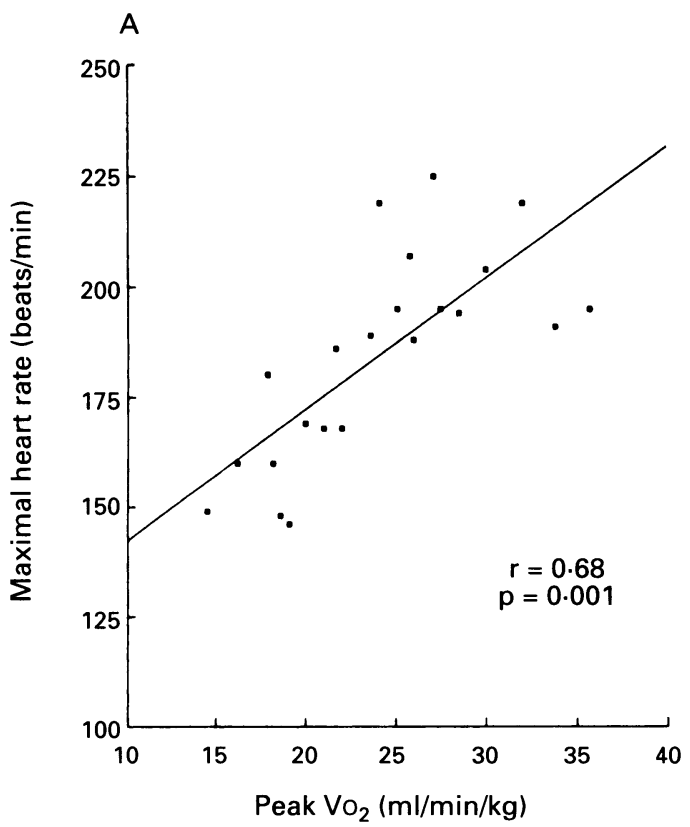



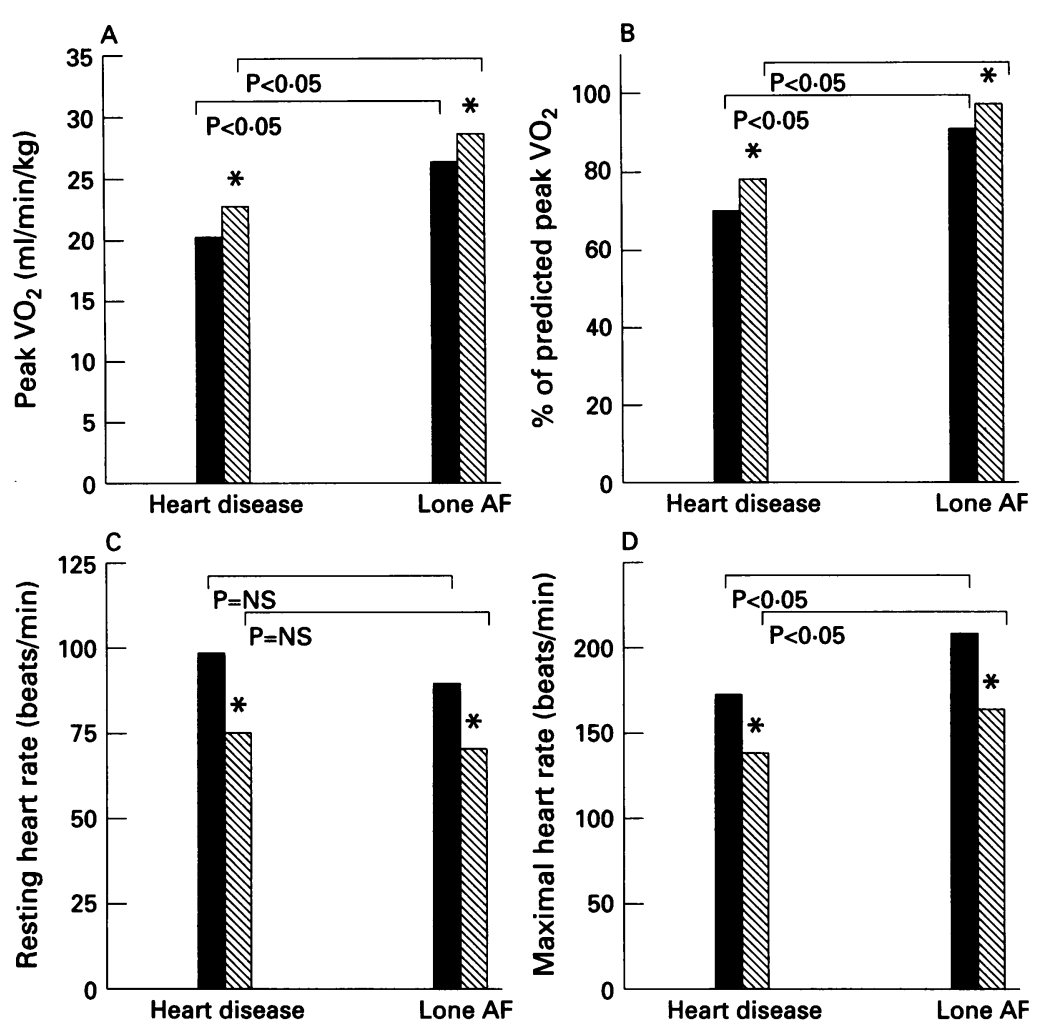

Before cardioversion 1 month SR

Figure 3 (A) Peak oxygen consumption, (B) peak oxygen consumption expressed as a percentage of the age and sex predicted maximum, $(C)$ resting heart rate, and $(D)$ maximal heart rate in atrial fibrillation $(A F)$ patients $(n=28)$ and without underlying heart disease $(n=9)$ before cardioversion and after 1 month of sinus $(S R)$ rhythm. $P<0.05$ versus values before cardioversion. Peak $V_{O_{2}}$, peak oxygen consumption.

that of controls, in patients with underlying heart disease it was only $80 \%$ of that in controls.

PREDICTORS OF PEAK OXYGEN CONSUMPTION DURING ATRIAL FIBRILLATION

Stepwise regression analysis, with pre-cardioversion peak $\mathrm{Vo}_{2}$ as the dependent variable, indicated that sex, age, and the presence of underlying heart disease were significant multivariate predictors of peak $\mathrm{Vo}_{2}$ during atrial fibrillation.

\section{Discussion}

Three previous studies used gas exchange analysis to study the effect of cardioversion on exercise capacity in patients with atrial fibrillation. ${ }^{11-13}$ As in our study, they showed an increase in peak $\mathrm{VO}_{2}$ after restoration of sinus rhythm. When Lundström and Karlsson studied 16 patients with atrial fibrillation they found an improvement in maximal oxygen uptake 1 month after successful cardioversion. ${ }^{13}$ This was accompanied by increased efficiency of ventilation. These four studies all showed a remarkably consistent improvement (approximately 10\%) in peak $\mathrm{Vo}_{2}$ after restoration of sinus rhythm.

Unlike the studies of Atwood et al and Lipkin et al we found that the improvement in peak $\mathrm{Vo}_{2}$ in patients who maintained sinus rhythm was not related to peak $\mathrm{Vo}_{2}{ }^{12}$ or left ventricular function. ${ }^{12}{ }^{29}$ Because we used similar methods and selection of patients, these differences probably reflect the small numbers of patients included in these studies. We believe that peak $\mathrm{Vo}_{2}$ should not be used to select patients who are expected to benefit most from cardioversion in terms of improvement in functional capacity.

\section{LONE ATRIAL FIBRILLATION VERSUS}

\section{UNDERLYING HEART DISEASE}

Atwood et al showed that before cardioversion patients with lone atrial fibrillation had significantly higher peak $\mathrm{Vo}_{2}$ values and maximal heart rates than those with underlying heart disease. ${ }^{5}$ This accords with our findings. However, unlike the study of Atwood et al baseline functional capacity in our patients with lone atrial fibrillation was lower than predicted for age and sex matched controls. Therefore, our findings suggest that the arrhythmia itself may be a factor limiting exercise. This is supported by the observation that peak $\mathrm{Vo}_{2}$ increased after successful cardioversion in these patients. Apparently, the excessive heart rate response during atrial fibrillation may not always adequately compensate for the loss of atrial contribution to ventricular filling in patients with lone atrial fibrillation. Increase in functional capacity after restoration of sinus rhythm may also have been promoted by an improvement in left ventricular function, caused by a more favourable heart rate response in these patients with relatively high heart rates during atrial fibrillation. ${ }^{30}$

\section{EXERCISE CAPACITY AND ARRHYTHMIA \\ OUTCOME}

The present study did not show that peak $\mathrm{VO}_{2}$ was a predictive factor for long-term arrhythmia outcome after cardioversion. In contrast, one previous study reported that a better functional state, expressed as New York Heart Association class, was associated with a longer arrhythmia-free episode after cardioversion. ${ }^{28}$ One possible explanation for the present finding is that the high arrhythmia recurrence rate, presumably caused by the long total duration of arrhythmia, precluded detection of peak $\mathrm{VO}_{2}$ as a predictive factor for arrhythmia outcome. This is supported by the observation that none of the established risk factors for predicting arrhythmia relapses was statistically significant in our study. An alternative explanation may be that patients with a relatively high peak $\mathrm{VO}_{2}$-that is, patients with lone atrial fibrillation-have an unfavourable long-term arrhythmia outcome ${ }^{31}$ (probably because of primary electrophysiological abnormalities of the atria), whereas patients with a relatively low peak $\mathrm{VO}_{2}$-that is, patient with coexistent heart disease-have a high recurrence rate caused by the underlying heart disease. This would also explain the inability to discriminate between a favourable and unfavourable long-term arrhythmia outcome by means of peak $\mathrm{Vo}_{2}$. Nevertheless, from a clinical point of view, our findings suggest that the opportunity to restore sinus rhythm should not be withheld from patients with atrial fibrillation and a low functional 
capacity merely because of an impaired functional status.

\section{PREDICTORS OF PEAK OXYGEN CONSUMPTION DURING ATRIAL FIBRILLATION}

In the present study the only clinical factors predicting peak $\mathrm{Vo}_{2}$ during atrial fibrillation were age, sex, and presence of underlying heart disease. These findings contrast with the results of an earlier study, which stressed the importance of maximal heart rate in predicting maximal oxygen consumption. ${ }^{5}$ In our study a significant relation between maximal heart rate and peak $\mathrm{Vo}_{2}$ was found only in patients with lone atrial fabrillation (figure $2 \mathrm{~A}$ ). The absence of a similar relation in patients with underlying heart disease was mainly the result of an excessive heart rate combined with a low peak $\mathrm{Vo}_{2}$ in many of these patients (upper left quadrant of fig 2B). Obviously, in patients with underlying heart disease and a low peak $\mathrm{Vo}_{2}$ the "normal" relation between functional capacity and heart rate response is lost. Presumably, an enhanced adrenergic drive ${ }^{32}$ and adaptive mechanisms in the peripheral circulation ${ }^{33} 34$ may be responsible for this low peak $\mathrm{Vo}_{2}$ despite a high heart rate during exercise in these patients.

\section{STUDY LIMITATIONS}

Although we compared results of patients maintaining sinus rhythm after cardioversion with a control group of patients remaining in atrial fibrillation, patients were not randomised to cardioversion or pharmacological rate control only. This may have introduced a bias leading to selection of patients in the control group who did not improve their exercise capacity for reasons other than arrhythmia outcome. However, at baseline, patient groups were similar, and established clinical indices for predicting relapse were similar in the two groups.

\section{CONCLUSIONS AND CLINICAL IMPLICATIONS}

Restoration of sinus rhythm improved peak $\mathrm{Vo}_{2}$ in patients with chronic atrial fibrillation. This holds both for patients with underlying heart disease and without. Also, functional state was not a predictive factor for long-term maintenance of sinus rhythm after cardioversion. Our findings suggest that cardioversion is the best method of improving functional capacity in patients with atrial fibrillation, irrespective of the presence of underlying heart disease and the functional state.

We thank the Netherlands Heart Foundation, The Hague (grant 60.091 ) for financial support.

1 Aberg H, Ström G, Werner I. Heart rate during exercise in patients with atrial fibrillation. Acta Med Scand 1972; 191:315-20.

2 Braunwald E. Symposium on cardiac arrhythmias: introduction with comments on the hemodynamic significance of atrial systole. $A m \mathcal{F}$ Med 1964;37:665-9.

3 Samet P, Bernstein W, Levine S. Significance of the atrial contribution to ventricular filling. Am $\mathcal{F}$ Cardiol 1965; 15:195-202.

4 Skinner NS, Mitchell JH, Wallace AG, Sarnoff SJ. Hemodynamic consequences of atrial fibrillation at constant ventricular rates. Am $\mathcal{F}$ Med 1964;36:342-51.

5 Atwood JE, Myers J, Sullivan M, et al. Maximal exercise testing and gas exchange in patients with chronic atrial fibrillation. $¥ \mathrm{Am}$ Coll Cardiol 1988;11:508-13.
6 Myers J, Froelicher VF. Optimizing the exercise test for pharmacologic investigations. Circulation 1990;82: 1839-46.

7 Sullivan M, Genter F, Savvides M, Roberts M, Myers J, Froelicher VF. The reproducibility of hemodynamic, electrocardiographic, and gas exchange data during treadmill exercise in patients with stable angina pectoris. treadmill exercise in pat

8 Weber KT, Kinasewitz GT, Janicki JS, Fishman AP. Oxygen utilization and ventilation during exercise in patients with chronic cardiac failure. Circulation 1982; 65:1213-23.

9 Elborn JS, Standford CF, Nicholls DP. Reproducibility of cardiopulmonary parameters during exercise in patients with chronic congestive heart failure. The need for a preliminary test. Eur Heart $\mathcal{f}$ 1990;11:75-81.

10 Franciosa JA. Exercise testing in chronic congestive heart failure. Am f Cardiol 1984;53:1447-50.

11 Atwood JE, Myers J, Sullivan M, et al. The effect of cardioversion on maximal exercise capacity in patients with chronic atrial fibrillation. Am Heart $\mathcal{F} 1989 ; 118: 913-8$.

12 Lipkin DP, Frenneaux M, Stewart R, Joshi J, Lowe T, McKenna WJ. Delayed improvement in exercise capacity after cardioversion of atrial fibrillation to sinus rhythm. Br Heart $\mathcal{F} 1988 ; 59: 572-7$.

13 Lundström $T$, Karlsson $O$. Improved ventilatory response to exercise after cardioversion of chronic atrial fibrillato ex to sinus rhythm. Chest 1992;102:1017-22.

14 Van Gelder IC, Crijns HJGM, Van Gilst WH, Van Wijk LM, Hamer HPM, Lie KI. Efficacy and safety of flecainide acetate in the maintenance of sinus rhythm after cainide acetate in the maintenance of sinus rhythm after
electrical cardioversion of chronic atrial fibrillation or atrial flutter. Am $\mathcal{F}$ Cardiol 1989;64:1317-21.

15 Patterson JA, Naughton J, Pietras RJ, Gunnar RM. Treadmill exercise in assessment of functional capacity of patients with cardiac disease. Am $\mathcal{F}$ Cardiol 1972; 30:757-62.

16 Van Den Broek SAJ, Van Veldhuisen DJ, De Graeff PA, Landsman MLJ, Hillege $\mathrm{H}$, Lie $\mathrm{KI}$. Comparison between New York Heart Association classification and peak oxygen consumption in the assessment of functional status and prognosis in patients with mild to moderate chronic congestive heart failure secondary to either ischemic or idiopathic dilated cardiomyopathy. $\mathrm{Am}$ Cardiol 1992;70:359-63.

17 Bruce RA, Kusumi F, Hosmer D. Maximal oxygen intake and nomographic assessment of functional aerobic impairment in cardiovascular disease. Am Heart $\mathscr{J}$ 1973;85:546-62.

18 Drinkwater BL, Horvath SM, Wells CL. Aerobic power of females, ages 10-68. F Geront 1975;30:385-94.

19 Hammond K, Froelicher VF. Normal and abnormal heart rate responses to exercise. Prog Cardiovasc Dis 1985;28 271-96.

20 Chikamori T, Counihan PJ, Doi YL, et al. Mechanisms of exercise limitation in hypertrophic cardiomyopathy. $f$ Am Coll Cardiol 1992;19:507-12.

21 Dittrich HC, Erickson JS, Schneiderman T, Blacky R, Savides T, Nicod PH. Echocardiographic and clinical Savides T, Nicod PH. Echocardiographic and clinical predictors for outcome of elective cardio

22 Hall J, Wood DR. Factors affecting cardioversion of atrial arrhythmias with special reference to quinidine. $\mathrm{Br}$ Heart f 1968;30:84-90.

23 Brodsky MA, Allen BJ, Capparelli EV, Luckett CR, Morton R, Henry WL. Factors determining maintenance of sinus rhythm after cardioversion of chronic atrial fibrillation with left atrial dilation. Am $\mathcal{F}$ Cardio 1989;63:1065-8.

24 Henry WL, Morganroth J, Pearlman AS, et al. Relation between echocardiographically determined left atrial size and atrial fibrillation. Circulation 1976;53:273-9.

25 Flugelman MY, Hasin Y, Katznelson N, Kriwisky M, Shefer A, Gotsman MS. Restoration and maintenance of sinus rhythm after mitral valve surgery for mitral stenosis. Am $\mathcal{F}$ Cardiol 1984;54:617-9.

26 Ewy G, Ulfers L, Hager WD, Rosenfeld AR, Roeske WR, Goldman S. Response of atrial fibrillation to therapy: role of etiology and left atrial diameter. $\mathcal{F}$ Electrocardiol role of etiology

27 Waris E, Kreus KE, Salokannel J. Factors influencing persistence of sinus rhythm after DC shock treatment of sistence of sinus rhythm after DC shock treatm
atrial fibrillation. Acta Med Scand 1971;189:161-6.

28 Van Gelder IC, Crijns HJ, Van Gilst WH, Verwer R, Lie KI. Prediction of uneventful cardioversion and maintenance of sinus rhythm from direct-current electrical carnance of sinus rhythm from direct-current electrical car-
dioversion of chronic atrial fibrillation or flutter. $A m \mathcal{F}$ dioversion of chronic
Cardiol 1991;68:41-6.

29 Atwood EJ. Exercise hemodynamics of atrial fibrillation In: Falk RH, Podrid PJ, eds. Atrial fibrillation: mechanisms and management. New York: Raven Press, 1992:145-63.

30 Xie B, Rodriguez LM, Schläpfer J, et al. Does left ventricular ejection fraction change after ablation of AV nodal conduction in patients with atrial fibrillation? [abstr] $\mathscr{f}$ Am Coll Cardiol 1992;19:228A.

31 DeSilva RA, Lown B. Cardioversion and atrial fibrillation Am Heart f 1980;100:881-95.

32 Cohn JN. Abnormalities of the peripheral sympathetic nervous system control in congestive heart failure. Circulation 1990;82:59-67.

33 Wilson JR, Martin JL, Schwarty Ferraro N. Exercise tolerance in patients with chronic heart failure: role of impaired nutritive flow to skeletal muscle. Circulation 1984;71:57-62.

34 Gosselink ATM, Smit AJ, Crijns HJGM, Lie KI Improvement of peripheral blood flow after cardioversion of atrial fibrillation [abstr]. Circulation 1992;82:70. 